ORIGINAL ARTICLES

\title{
SPIROMETRIC SCREENING OF CHRONIC OBSTRUCTIVE PULMONARY DISEASE IN SMOKERS PRESENTING TO TERTIARY CARE CENTRE
}

\author{
HAMMAD ALI QAZI $^{1}$, JAMIL AHMED SOOMRO ${ }^{1}$, TAHIRA KALISAR SOOMRO ${ }^{1}$, FAHMIDA AKHTAR \\ SOOMRO $^{2}$, FAHIRA RASHEED ${ }^{1}$, ANJUM HASHMI ${ }^{1}$
}

\begin{abstract}
Objective: To determine the frequency of Chronic Obstructive Pulmonary Disease (COPD) by spirometric screening in smokers presenting to tertiary care center.

Design: This Cross sectional study was carried out at the Medical department, Civil Hospital Hyderabad from April 2006 to September 2006. The main outcome variables were frequency of COPD in smokers, presenting symptoms and proportion of COPD severity classification.

Results: The mean age of the clients was $39.77 \pm 6.30$ years. The main symptoms of the study population were 75 (75\%) patients have cough, 53 (53\%) have sputum and 34 (34\%) have dyspnoea. The spirometric results showed $39(39 \%)$ smokers had study diagnosis of COPD with $19(19 \%)$ had mild,12 (12\%) had moderate and $8(8 \%)$ smokers had severe obstruction.

Conclusion: The prevalence of COPD in smokers using spirometry in our population is high (39\%) as compared to international studies. This showed a great need and desire of screening for COPD in target population of smokers in our setting. Although effectiveness of screening in terms of smoking cessations and delay of progression of COPD should be calculated in order to make it national guideline.
\end{abstract}

Key words: Chronic Obstructive Pulmonary Disease; Screening; Smokers.

\section{Introduction:}

Chronic Obstructive Pulmonary Disease (COPD) is a global problem. According to World Bank reports it accounts for 29 million disability-adjusted life-years (DALYS) and 1 million years of life are lost per annum around the world. ${ }^{1}$ Many studies have shown COPD prevalence to be around 10 to $15 \%$ in smokers. ${ }^{1}$ A US based study has showed 4 in 5 patients with COPD are current or former smokers. ${ }^{2}$ Literature on COPD screening for smokers in primary care remains controversial. But there is increasing evidence to show that spirometric screening and frequency determination of people with moderate or severe COPD in smokers can significantly improves rates of smoking cessation as compared to rates of cessation in the otherwise general population. ${ }^{3}$

Our literature review clearly suggests weakness of epidemiological data in our country. Thus we planned to determine the frequency of COPD in smokers using spirometry as a standard technique.

\section{Methodology:}

We conducted a cross sectional study in department of Medicine Civil Hospital Hyderabad from April 2006 to September 2006 in smokers presenting to tertiary care center. The sample size of the study was 100 patients selected through non probability purposive sampling. The inclusion criteria were all males who are current smokers of age $>30$ years with smoking history of more than seven pack years, giving informed consent were included. Whereas factory workers, those living near the factories and exposed to chemicals like exposures to coal mine dust, cotton dust, silica and grain dust were excluded in the study. Patients of ischemic heart disease, having myocardial infarction in the last one month or having chest pain at rest or on exertion were also excluded from the study. Finally patients with co-morbidities like diabetes and TB., debilitating diseases, very old age

1. RTMC, CPSP, Karachi

2. Lady Dufferin Hospital Karachi

Correspondence : Dr Hammad Ali Qazi, Senior Research Analyst, RTMC Department, CPSP, Karachi, Pakistan, Email: hammadali400@hotmail.com 
(>60 years), previously diagnosed as COPD, taking treatment for COPD were also excluded from the sample.

The main outcome variable of the study was presence of COPD. The effect modifiers were controlled by strict exclusion criteria. The close-ended questionnaire along with proper training of the co-researchers minimizes interviewer bias.

All the selected patients were interviewed by co researcher. COPD was confirmed by spirometry performed by trained technician of at least five years experience. A study diagnosis of COPD was defined as airway obstruction as measured by FEV1/FVC $<0.70$ measured by trained technician.

The severity of COPD was also diagnosed using Global Initiative for Chronic Obstructive Pulmonary disease (GOLD) by a trained technician in front of coresearcher. The classification cutoffs were mild FEV1/ FVC $<0.70$ (FEV1 $\geq 80 \%$ predicted), moderate FEV1/ FVC $<0.70$ (50\% $\leq \mathrm{FEV} 1<80 \%$ predicted), severe FEV1/FVC $<0.70(30 \% \geq$ FEV1 $<50 \%$ predicted $)$ and very severe FEV1/FVC $<0.70$ (FEV1 $<30 \%$ predicted or $\mathrm{FEV} 1<50 \%$ predicted plus chronic respiratory failure)

The data was entered and analyzed in SPSS 12. The quantitative variables include age, age of starting smoking, number of cigarettes smoked per day, expressed as means and S.D. The qualitative variables include sex, occupation, presenting symptoms (cough, sputum and dyspnoea), COPD along with its severity classification (mild, moderate, severe and very severe obstruction), were expressed as percentages. No analytical test was applied.

\section{Results:}

The mean age of the clients was $39.77 \pm 6.30$ years. There were 4 (4\%) businessmen, $3(3 \%)$ teachers, $7(7 \%)$ drivers, 14 (14\%) farmers, 48 (48\%) laborers and 24 (24\%) shopkeepers (Table-I). The mean age of starting smoking of the patients was $22.35 \pm 5$. 34 years. The mean number of cigarettes smoked per day was $17.65 \pm 5.70$ cigarettes. According to the interpretation of Spirometric results, 61 (61\%) smokers had normal spirometry whereas 39 (39\%) smokers had study diagnosis of COPD. Using the about 19 (19\%) smokers had mild obstruction, 12 (12\%) smokers had moderate obstruction and 8 (8\%) smokers had severe obstruction none have very severe obstruction. The main symptoms of the study population were cough (75, $75 \%)$, sputum $(53,53 \%)$ and dyspnoea (34, 34\%) respectively (Table-II). Finally the distribution of mean outcome of spirometry according to severity of smoking history is shown in Table-III.

\section{Table-I}

Descriptive statistics of socio demographic data

\begin{tabular}{lcc}
\hline Age (Years) & No. of patients & Percentage \\
\hline $30-40$ & 64 & 64.0 \\
$41-50$ & 30 & 30.0 \\
$51-60$ & 6 & 6.0 \\
Mean \pm SD & $39.77 \pm 6.30$ & \\
Occupation & & \\
Businessman & 4 & 4.0 \\
Teacher & 3 & 3.0 \\
Driver & 7 & 7.0 \\
Farmer & 14 & 14.0 \\
Laborer & 48 & 48.0 \\
Shopkeeper & 24 & 24.0 \\
Total & 100 & 100.0 \\
Socioeconomic status & & \\
Lower class(Monthly income & & \\
$<5$ thousand rupees) & 9 & 9.0 \\
Middle class(Monthly income & & \\
5-30 thousand rupees) & 88 & 88.0 \\
Upper class(Monthly income & & \\
$>$ 30 thousand rupees) & 3 & \\
\hline Total & 100 & \\
\hline
\end{tabular}

Table-II

Symptoms of Presentation

\begin{tabular}{lcc}
\hline History & Yes & No \\
\hline Cough & 75 & 25 \\
Sputum & 53 & 47 \\
Dyspnoea & 34 & 66 \\
\hline
\end{tabular}


Table-III

Distribution of mean outcome of spirometry according to severity of smoking history $(n=100)$

\begin{tabular}{lccc}
\hline & $\begin{array}{c}7-10 \text { pack year } \\
(\mathrm{n}=41)\end{array}$ & $\begin{array}{c}11-20 \text { pack year } \\
(\mathrm{n}=40)\end{array}$ & $\begin{array}{c}>20 \text { pack year } \\
(\mathrm{n}=19)\end{array}$ \\
& Mean $\pm \mathrm{SD}$ & Mean $\pm \mathrm{SD}$ & Mean $\pm \mathrm{SD}$ \\
\hline FVC & $93.28 \pm 11.98 \%$ & $82.79 \pm 13.81 \%$ & $72.14 \pm 14.076 \%$ \\
FEV1 & $81.70 \pm 16.34 \%$ & $61.50 \pm 20.95 \%$ & $53.10 \pm 18.53 \%$ \\
FEV1/FVC & $86.93 \pm 19.36 \%$ & $73.88 \pm 19.88 \%$ & $63.55 \pm 14.73 \%$ \\
\hline
\end{tabular}

\section{Discussion:}

The concept of upstream and downstream approaches to public health interventions were first popularized by John McKinlay. ${ }^{4}$ Downstream interventions are focused primarily at the individual level towards tertiary prevention with an aim to change adverse health behaviours. ${ }^{5,6}$ Whereas upstream interventions are targeted at group level and includes efforts at primary level that help in decreasing risk exposure and keeping healthy people healthy. In general upstream interventions are passive interventions, requiring least amount of effort and hence more effective in longer terms. ${ }^{5,6}$

Currently COPD is the 12 th leading cause of disability worldwide expected to be fifth by $2020 .{ }^{1}$ Globally, smoking is a major cause of COPD and symptoms typically present in mid to later life. ${ }^{7}$ Smoking is a major risk factor of COPD and increases with aging due to changes in pulmonary function. ${ }^{8} \mathrm{~A}$ study conducted by Trofor has showed that smoking cessation as mandatory and beneficial in COPD. ${ }^{9}$

The results of this study showed higher frequency of COPD in smokers (39\%). Further 19 (19\%) smokers had mild obstruction, $12(12 \%)$ smokers had moderate obstruction and $8(8 \%)$ smokers had severe obstruction.

There are many studies that have shown high prevalence of COPD in smokers. ${ }^{2,3,10}$

A study showed $34.9 \%$ of people diagnosed with COPD were smokers compared with $22.4 \%$ of those without. ${ }^{11}$ In a study by Gingter COPD prevalence in smokers was $6.9 \% .{ }^{12} \mathrm{~A}$ study conducted in Turkey showed $6.9 \%$ of the participants (general population) were found to have COPD with the prevalence of COPD was $18.1 \%$ in current smokers. ${ }^{13}$ A study in Japan showed overall, $22.5 \%$ of patients were current smokers. ${ }^{14}$ A study by Pelkonen showed approximately one-quarter of smokers can be affected by clinically significant chronic obstructive pulmonary disease. $^{9}$

A study was conducted in Israel that showed COPD prevalence of about $22 \%$ in smokers. ${ }^{15} \mathrm{~A}$ study in China showed the smoking rate among COPD patients was significantly higher than that among the controls. ${ }^{16}$ A study by Godoy showed that about 57 (36.1\%) smokers met the criteria for COPD out of 158 smokers. ${ }^{10}$ A study in China showed the overall prevalence of COPD (in the general population) was $8.2 \% .{ }^{17} \mathrm{~A}$ study conducted by Tatsumi also showed $15 \%$ of chronic smokers may develop COPD. ${ }^{18}$

Our study has also showed a higher prevalence COPD of around $39 \%$ in smokers. But few studies have also shown a very low prevalence of COPD in smokers. ${ }^{1,12}$ Our study only included male patients the justification was studies have shown COPD to be more frequently occurred in males than females mostly due to predominance of smoking in males. ${ }^{19,20}$ Another study has showed the presence of COPD was significantly lower among women compared to men. ${ }^{21}$

A study in Israel has showed that there was no correlation between pack-years smoking and development of COPD, but there was a relative correlation of pack-years smoking and severity of COPD, particularly in the older group. ${ }^{15}$ Our study also showed decrease in FEV1/FVC (severe COPD) with increase in pack years (see Table-III)

Study by Plywaczewski has showed that majority of examined subjects presented with COPD symptoms of cough (62.7\%), expectoration (68.8\%) and dyspnoea (50.2\%). ${ }^{22}$ Similarly study by Bednarek has showed one third of examined declared morning cough (36.9\%) or sputum production (34.8\%), or both symptoms (26.7\%). ${ }^{23}$ While our study showed that about 75 (75\%) patients have cough, 53 (53\%) have sputum and 34 (34\%) have dyspnoea. 
A study by Godoy showed out of the 39 newly diagnosed individuals, $38(97,4 \%)$ presented the mild/moderate for of the disease, and only 1 (2,6\%) had severe COPD. ${ }^{10}$ While in our study out of 39 patients 19 (48.7\%) have mild obstruction, $12(30.76 \%)$ have moderate and 8 (20.5\%) have severe obstruction.

The main limitation of the study was a hospital based study not true representative of smokers in general community. But then it would be more advisable and feasible to perform screening in those smokers approaching at a tertiary center. So our results can be used in developing screening strategies to all smokers presenting to tertiary hospitals. The other limitation was, we were unable to control the effect of atmospheric pollution in developing COPD in our target population of smokers. But as our main objective was to provide rationale for screening by determining frequency of COPD in smokers and not association. Thus it does not affect our study objective and outcomes.

\section{Conclusion:}

The higher prevalence of COPD in smokers clearly showed the effectiveness and a rationale to conduct screening in the most target group (smokers). But father studies with larger and more multi centric settings involving health economic models should be conducted in order to develop national recommended guidelines in future.

\section{Acknowledgements:}

We acknowledge the efforts of RTMC, CPSP Karachi statisticians Iqbal Mujtaba, Syed Amir, Sajid and Department of Medicine Civil Hospital Hyderabad.

\section{References:}

1. Stang P, Lydick E, Silberman C, Kempel A, Keating ET. The prevalence of COPD: using smoking rates to estimate disease frequency in the general population. Chest 2000; 117(5) Suppl 2: 354S-9S.

2. Screening for COPD with Spirometry. http:// www.medscape.com/viewarticle/571200. March 10, 2009

3. Garcia-Aymerich J, Lange P, Benet M, Schnohr P, Antó JM. Regular physical activity modifies smoking-related lung function decline and reduces risk of chronic obstructive pulmonary disease: a population-based cohort study. Am J Respir Crit Care Med 2007; 175(5): 458-63.

4. McKinlay JB, Marceau LD. Public health matters. To boldly go. Am J Public Health 2000; 90: 25-33.
5. Kelly MP, Mcdaid D. Economic appraisal of public health interventions. 2005. URL: http://www.nice. org.uk/media/43B/06/Economic_appraisal_of_ public_health_interventions.pdf [Accessed 11 Nov 2008].

6. Lytle LA, Fulkerson JA. Assessing the dietary environment: examples from school-based nutrition interventions. Public Health Nutr 2002; 5: 893-9.

7. Schofield I, Kerr S, Tolson D. An exploration of the smoking-related health beliefs of older people with chronic obstructive pulmonary disease. J Clin Nurs 2007; 16(9): 1726-35.

8. Arioka H. [The programs for smoking cessation] Nippon Rinsho 2007; 65(4): 724-9.

9. Trofor A, Frãsilã EI. [The habit of smoking—a sure step towards COPD] Pneumologia 2007; 56(2): 8590.

10. Godoy I, Tanni SE, Coelho LS, et al. Smoking cessation program as a tool for the early diagnosis of chronic obstructive pulmonary disease. J Bras Pneumol 2007; 33(3):282-6.

11. Does spirometric screening of moderate to severe COPD patients improve their smoking cessation rates? Respiratory Medicine: COPD update 2007; 3(2): 66 .

12. Gingter C, Wilm S, Abholz HH. Is COPD a rare disease? Prevalence and identification rates in smokers aged 40 years and over within general practice in Germany. Fam Pract 2008. [Epub ahead of print]

13. Gunen H, Hacievliyagil SS, Yetkin O, Gulbas G, Mutlu LC, Pehlivan E. Prevalence of COPD: first epidemiological study of a large region in Turkey. Eur J Intern Med 2008; 19(7): 499-504.

14. Hirayama F, Lee AH, Binns CW, Tanikawa Y. Persistent smoking by Japanese patients within four years from diagnosis of chronic obstructive pulmonary disease. Addict Behav. 2008; 33(9): 12358.

15. Stav D, Raz M. Prevalence of chronic obstructive pulmonary disease among smokers aged 45 and up in Israel. Isr Med Assoc J 2007; 9(11): 800-2.

16. Xu F, Yin X, Shen H, Xu Y, Ware RS, Owen N. Better understanding the influence of cigarette smoking and indoor air pollution on chronic obstructive pulmonary disease: a case-control study in Mainland China. Respirology 2007; 12(6): 891-7.

17. Zhong N, Wang C, Yao W, et al. Prevalence of chronic obstructive pulmonary disease in China: a large, 
population-based survey. Am J Respir Crit Care Med 2007 15; 176(8): 753-60.

18. Tatsumi K. [Effects of smoking on the pathogenesis of COPD] Nippon Rinsho 2007;65(4):605-10.

19. Feinleib M, Rosenberg HM, Collins JG, Delozier JE, Pokras R, Chevarley FM.Trends in COPD morbidity and mortality in the United States. Am Rev Respir Dis. 1989; 140(3 Pt 2): S9-18.

20. Davis RM, Novotny TE. The epidemiology of cigarette smoking and its impact on chronic obstructive pulmonary disease. Am Rev Respir Dis. 1989; 140(3 Pt 2): S82-4.
21. Loganathan RS, Stover DE, Shi W, Venkatraman E. Prevalence of COPD in women compared to men around the time of diagnosis of primary lung cancer. Chest. 2006; 129(5): 1305-12.

22. Pywaczewski R, Bednarek M, Górecka D, Puœciñska E, Nowiñski A, Zieliñski J. [Early, targeted population based screening for COPD. Preliminary study] Pneumonol Alergol Pol. 1999; 67(9-10): 41621.

23. Bednarek M, Plywaczewski R, Górecka D, Puœciñska E, Nowiñski A, Zieliñski J. [Early detection of COPD in smokers from Warsaw using spirometric screening] Pneumonol Alergol Pol 2002; 70(3-4): 139-47. 